\title{
$O$ varejo moderno de alimentos: modernidade $e$ insegurança alimentar e nutricional
}

Newton Narciso Gomes Junior ${ }^{1}$ Bárbara Loureiro Borges ${ }^{2}$

\begin{abstract}
Resumo: O quadro desanimador da questão alimentar brasileira é o cenário no qual se desenvolve o presente ensaio cujo olhar volta-se para a dimensão bi - fronte do problema: o sistema de abastecimento alimentar da produção ao varejo e as determinações do sistema quanto àquilo que se come desde a qualidade e forma que se organiza a oferta dos alimentos no mercado. Para darmos conta dessa intenção, nos dedicamos inicialmente a entender como a modernização do sistema varejista de alimentos implementada nos anos 1970 e que teve como marca a consolidação dos supermercados em substituição à diversidade de equipamentos varejistas convencionais, mercados, feiras, quitandas, empórios e armazéns, que respondiam pelo abastecimento alimentar urbano, especialmente nas classes populares. Nesse percurso nos debruçamos, também, sobre a ressignificação da ideia de comida e como isso abriu a possibilidade para o ingresso marcante de alimentos artificiais baratos e inseguros na dieta do brasileiro, contribuindo de um lado para a reduzir o custo de reprodução da força de trabalho ao mesmo tempo em que compensou a redução da disponibilidade de tempo para o preparo de refeições ante a compressão do espaço - tempo no cotidiano da população citadina.
\end{abstract}

Palavras-Chave: Segurança e Insegurança Alimentar e Nutricional; Supermercados; Comida; Soberania Alimentar.

AbSTRACT :The disheartening Picture of Brazilian's food question is the scenario in which the present essay is developed whose perspective turns to the twofold dimension of the problem: the food supply system of retail production and the determinations of the system as to what one eats from the quality and form that organizes the food supply in the market. In order to realize this intention, we initially set out to understand how the modernization of the retail food system implemented in the 1970s and marked by the consolidation of supermarkets as a substitute for the diversity of conventional retail equipment, markets, fairs, warehouses, which responded for the urban food supply, especially in the popular classes. In this course we also look at the re-signification of the idea of food and how it opened the possibility for the marked entry of cheap and insecure artificial foods into the Brazilian diet, contributing on the one hand to reduce the cost of reproduction of the workforce while at the same time compensating for the reduction of the availability of time for the preparation of meals before the compression of the space - time in the daily life of the city population.

KEYwORDS: Food and Nutrition Security and Insecurity; Supermarkets; Food; Food Sovereignty.

\footnotetext{
${ }^{1}$ Membro permanente do Programa de Pós Graduação em Meio Ambiente e Desenvolvimento Rurral MADER/FUP/UnB, lider do Grupo de Pesquisa CNPQ Abastecimento e Comida, pesquisador do Núcleo de Estudos Agrários NEAGRI - CEAM/ UnB. E-mail: swnewtongomes@gmail.com

${ }^{2}$ Engenheira Florestal, UnB, Mestre em Meio Ambiente e Desenvolvimento Rural PPGMAder/FUP/UnB. Pesquisadora do Diretório de Pesquisa Comida e Abastecimento, CNPQ/UnB. E-mail: bab.loureiro@gmail.com
} 


\section{INTRODUÇÃ̃o}

Atualmente a humanidade produz mais alimentos do que em toda a sua história. Segundo dados de Jean Ziegler, relator especial durante os anos de 2000 a 2008 sobre Direito à Alimentação da ONU, são produzidos hoje, alimentos para 12 bilhões de pessoas, comida suficiente para atender às necessidades alimentares de 1,5 vezes a população vivente na Terra (ZIEGLER, 2012). A contradição se acentua quando observamos que no mundo todo cerca de 821 milhões de pessoas estão em situação crônica de fome, enquanto outros 641 milhões são obesos (FAO, 2018).

Esse paradoxo de viver num mundo de famintos e de obesos escancara as falhas de um sistema alimentar submetido, sem regulação ou controle, às regras e necessidades do mercado e do capital. A consequência mais imediata desse cenário é a persistência da condição de insegurança alimentar, seja por restrições de acesso aos alimentos seja pelo acesso inadequado à comida. Em ambos os casos, a assimetria entre a renda disponível e os preços dos alimentos se apresenta como causa do desarranjo que vitima em alguma medida, mais da metade da população mundial.

Partindo da premissa de que o sistema agroalimentar não se reduz apenas a um simples modelo de produção de refeições, destaca-se nessa trama a velada relação direta entre os fenômenos da fome e da obesidade, conectados pela cadeia de distribuição que leva os alimentos do campo até a mesa do consumidor (ESTEVE, 2017; PATEL, 2007), em uma entrelaçada rede de diferentes intermediários e interesses que beneficiam principalmente a indústria agroalimentar e os supermercados. Deste modo, podemos concluir que a fome e a obesidade são sintomas do mesmo problema cuja superação impõe-se como urgente.

Segundo o relatório da Organização das Nações Unidas para Alimentação e Agricultura, em 2014 o Brasil saiu do Mapa Mundial da Fome ${ }^{3}$ pela forte redução do número de pessoas nessa situação verificada nas últimas décadas (FAO, 2016). No entanto, esse fato não se deu por questões relacionadas à produção e distribuição de alimentos ou por uma efetiva política de segurança e soberania alimentar, mas sim por questões econômicas relacionadas às políticas sociais de inclusão que permitiram o acesso da população mais pobre a esses alimentos.

Mas, se por um lado sair do Mapa da Fome é um avanço importante, de outro, conviver com cerca de $50 \%$ da população exposta às consequências devastadoras para a saúde em decorrência do excesso de peso sinaliza que o problema da insegurança alimentar e nutricional não foi superado. Dados da pesquisa VIGITEL de 2016 apontam um aumento de $60 \%$ da obesidade em adultos no Brasil nos

\footnotetext{
${ }^{3} \mathrm{O}$ Mapa Mundial da Fome relaciona em quais países há parte significativa da população ingerindo uma quantidade diária de calorias inferior ao recomendado. Para sair do mapa, o país deve ter menos de $5 \%$ da população ingerindo menos calorias do que o recomendado.
} 
últimos dez anos (MINISTÉRIO DA SAÚDE, 2017). E em relação à fome, as previsões para os próximos anos sinalizam que o quadro de IA tende a piorar em razão das mudanças políticas que determinaram o congelamento dos investimentos sociais por 20 anos, o recrudescimento do desemprego que atinge pelo menos $13 \%$ da população economicamente ativa, além das constantes investidas do governo desde 2015 contra os programas de transferência de rendas. (GTSCA2030, 2017).

O quadro desanimador da questão alimentar brasileira apresentado nas passagens anteriores é o cenário no qual se desenvolve o presente ensaio cujo olhar volta-se para a dimensão bi - fronte do problema: o sistema de abastecimento alimentar da produção ao varejo e as determinações do sistema quanto àquilo que se come desde a qualidade e forma que se organiza a oferta dos alimentos no mercado.

Para darmos conta dessa intenção, nos dedicamos inicialmente a entender como a modernização do sistema varejista de alimentos implementada nos anos 1970 e que tiveram como marca a consolidação dos supermercados em substituição à diversidade de equipamentos varejistas convencionais, mercados, feiras, quitandas, empórios e armazéns, que respondiam pelo abastecimento alimentar urbano, especialmente nas classes populares. Nesse percurso nos debruçamos, também, sobre a ressignificação da ideia de comida e como isso abriu a possibilidade para o ingresso marcante de alimentos artificiais baratos e inseguros na dieta do brasileiro, contribuindo de um lado para a reduzir o custo de reprodução da força de trabalho ao mesmo tempo em que compensou a redução da disponibilidade de tempo para o preparo de refeições ante a compressão do espaço - tempo no cotidiano da população citadina.

\section{AS TRANSFORMAÇões No SISTEMA DE ABASTECIMENTO ALIMENTAR: RAÍZES} Da Insegurança Alimentar

Os supermercados no Brasil, ganham força na trilha da urbanização tardia experimentada pelo país nos anos finais da década de 1960 e a seguinte, a partir de incentivos governamentais dentro da política de modernização do abastecimento que em tese deveria reduzir intermediações e transferir para os consumidores as vantagens de escala que aquele equipamento poderia oferecer.

$\mathrm{Na}$ realidade, dois movimentos ocorreram com a presença mais ativa dos supermercados na cena do varejo de alimentos; de um lado, a difusão de um espetacular rol de alimentos industrializados, inovadores que permitiam a estocagem por períodos dilatados de tempo, demandavam menos tempo no preparo das refeições e eram mais baratos que os gêneros in natura que compunham a cesta de alimentos tradicional. O movimento seguinte decorre deste primeiro. Os 
supermercados pelas vantagens de preços que oferecem, em pouco tempo fizeram com que, praticamente, desaparecesse a rede capilar de varejo convencional, capturando para si toda demanda solvente de alimentos, produtos de higiene e limpeza dentre outros itens.

O modelo de varejo adotado no Brasil se baseou essencialmente no autosserviço ${ }^{4}$ norte-americano que, operando em larga escala e utilizando tecnologias de estoque e armazenamento, possibilitou o barateamento do preço de produtos secos e molhados (LEDA, 2017).

Em apenas um ano, entre os anos de 1969 e 1970, os supermercados aumentaram sua participação no varejo de alimentos de 1\% para 13\% (SUPERMERCADO MODERNO, 2010). No início dos anos de 1970, os supermercados já representavam 26\% das vendas de gênero alimentícios do mercado brasileiro (ROJO, 1998). Destaca-se, ainda nos anos 1970, a chegada da rede francesa Carrefour em 1975 no Brasil, que introduziu um novo layout e mix de mercadorias no setor, com ampla área de vendas e estacionamento.

Devido à forte política fiscal de incentivo do Estado $^{5}$ e a articulação com o capital internacional, o arranjo de autosserviço se difundiu rapidamente no Brasil como uma nova prática de consumo, tornando os supermercados com sua ampla exposição de novos produtos industrializados em símbolos de modernidade.

Apesar das crises econômicas da década de 80, para manter a margem financeira de ganhos, os supermercados aumentaram seu volume de vendas, por meio da diferenciação e da diversificação na linha de produtos, o que era possível pelo sistema de ganho financeiro baseado na diferença praticada entre os prazos de pagamento de fornecedores (à prazo) e de recebimento de vendas (à vista) (CYRILLO, 1987; BELIK, 1999). Ou seja, as vantagens de custo associadas à alta escala de operações de compras permitiam a fixação de preços mais estáveis e garantiam a competitividade do setor. A forma de pagamento à vista também determinou que o público consumidor fosse de alta renda, influenciando a instalação inicial dos supermercados em bairros mais ricos ou em zonas mais afastadas de difícil acesso sem o uso de automóvel (SAAB; GIMENEZ, 2000).

É nesse sentido que os supermercados inseriram uma dupla revolução em relação à forma de adquirir, consumir e se relacionar com os alimentos. Conforme afirma Patel (2008), os supermercados são invenções patenteadas e que respondem a uma necessidade específica em um tempo e local específico em que foram concebidos.

\footnotetext{
${ }^{4}$ No sistema de autosserviço os clientes escolhem a mercadoria nas prateleiras do estabelecimento e fazem o pagamento nos check-outs, onde estão dispostas as caixas registradoras.

${ }^{5}$ Em 1968, a lei n ${ }^{\circ} 7208$ reconheceu os supermercados como uma categoria diferenciada de varejo de alimentos e que, portanto, deveriam ter uma carga tributária à parte.
} 
Essa dupla dinâmica, segundo o autor, diz respeito à expansão do consumo de massa de um tipo de produto adequado à dinâmica de agregação de valor e de comercialização em larga escala: enquanto a revolução técnica deu conta do barateamento e da adequação do alimento a um outro ritmo de vida nas cidades, bem como às condições de transporte e comercialização em larga escala, a intervenção educativa se instaurou pela difusão de novos produtos e novos hábitos alimentares, bem como por uma nova forma de se expor e adquirir os produtos.

Essas características deram condições para que os supermercados se firmassem como polarizadores no mercado de alimentos, intensificando a estratificação do consumo e do tipo de acesso aos alimentos.

Com a consolidação do segmento moderno de varejo alimentar, o sistema convencional que se assentava na operação de equipamentos tais como feiras livres, mercados, quitandas, mercadinhos e armazéns definhou. A impossibilidade desses equipamentos tradicionais pela pequena escala de suas vendas alcançarem a escala de compras que permitiria a prática de preços equivalentes aos praticados pelos supermercados, reforçou a assimetria entre renda e preços dos alimentos nos setores populares, agravando sobremaneira as condições de insegurança alimentar e nutricional por restrições de acesso.

A condição de vendas exclusivamente à vista e a localização das lojas de autosserviço em regiões de maior densidade populacional e renda ou em espaços cujo acesso dependia de transporte individual geram uma situação paradoxal. |Aos segmentos mais pobres da sociedade só restava pagar mais caro pelos alimentos oferecidos pelas lojas convencionais localizadas nos bairros onde viviam ante a impossibilidade de mobilidade que lhes permitissem frequentar os novos espaços de varejo; o pequeno varejo das periferias, por sua vez abasteciam-se nos supermercados. As vantagens de preços conseguidas nessa operação, o varejo tradicional acrescentava sua margem de comercialização que incluía os riscos de inadimplência que o fornecimento à crédito, acarretava.

Ademais, a renda nesses segmentos sempre fora insuficiente para que as necessidades alimentares fossem preenchidas adequadamente, assim, era recorrente entre os consumidores, buscarem no crédito oferecido pelos comerciantes locais a fórmula para "esticar" o salário complementando a despesa com comida. Essa equação é a que oferece base para que nas periferias os preços dos alimentos sejam mais caros que nos centros onde prevalecem um padrão de renda mais elevada, decorrendo disto o paradoxo clássico do abastecimento, segundo o qual, os mais pobres se vêm obrigados a comprometerem uma parcela maior da renda disponível para gastos com alimentação do que os mais ricos.

Dessa condição para o avanço dos supermercados em direção aos bairros 
populares mais consolidados foram poucos anos. Já em meados dos anos 1980 a supremacia do varejo moderno praticamente extinguira o comércio tradicional das periferias menos estruturadas, zonas de expansão das fronteiras urbanas nas quais prevalecem a concentração da pobreza espalhada em aglomerados de população rarefeita. Essa conformação, baixa renda, e população ocupante espalhada condena desde sempre amplos segmentos populacionais a conviverem com desertos alimentares, ou seja, espaços vazios de opções de abastecimento nos quais as opções de compra praticamente resumem-se a alimentos artificiais na forma de salgadinhos, biscoitos, refrigerantes e afins ofertados em equipamentos precários de conveniência.

A crise econômica instalada no país no início dos anos 1990 e o confisco das poupanças que levou à redução da quantidade de moeda em circulação, o setor dos supermercados foi atingido pela queda nas vendas e teve seu ganho financeiro reduzido. A reação do setor foi introduzir mais linhas de produtos, aumentando o mix de mercadorias e visando baixar o custo e o preço (BELIK, 1999). Nesse período os hortifrutigranjeiros passaram a fazer parte da linha de produtos dos supermercados, tornando as Centrais (CEASA) obsoletas para o varejo.

O resultado dessa reação se deu de forma diferente no setor, enquanto as grandes redes que possuíam melhores condições de negociação com os fornecedores conseguiram se reestabelecer, as empresas menores que possuíam menos poder de negociação com os fornecedores passaram por situações de inadimplência e consequente quebra ao tentar competir com prazos e financiamentos ao consumidor semelhantes aos praticados nos grandes supermercados (BELIK, 1999).

Ainda como forma de driblar a crise econômica, os grandes supermercados se expandiram rapidamente para as periferias urbanas, em bairros mais estruturados, com características de polos regionais, massificando a sua pauta de produtos para todas as faixas de renda e rompendo com a lógica do paradoxo do abastecimento que ofertava produtos mais diversificados a preços mais baratos às classes mais ricas (REARDON; BERDEGUÉ, 2002).

O resultado foi o aumento colossal na concentração do setor de distribuição varejista, que associadas às limitações e abandono das políticas de organização do abastecimento alimentar pelo Estado e as vantagens competitivas dos supermercados, permitiram que as redes varejistas internacionais consolidassem o processo de dominação e verticalização do setor, inserindo novas tecnologias, logísticas de coordenação e controle da definição de preços e qualidade dos produtos.

No Brasil, nos anos de 1999 a 2001, os supermercados foram responsáveis por cerca de $85 \%$ do abastecimento nacional de produtos de grande consumo, com destaque para a rede Carrefour, líder de faturamento nesse período (SILVEIRA; 
SANTOS, 2001; SAAB; GIMENEZ, 2000). O volume da venda de alimentos nos supermercados, em 2002, chegou a 44\%, sendo controlado por apenas 0,9\% estabelecimentos (FARINA et al., 2005), demonstrando o predomínio dos supermercados no abastecimento alimentar.

Em 2000, apenas 05 empresas eram responsáveis por 33\% do faturamento bruto do segmento varejista de alimentos no Brasil (SAAB; GIMENEZ, 2000). Em 2015, apenas cinco empresas concentravam $58 \%$ do faturamento dos supermercados (ABRAS, 2016). A empresa Companhia Brasileira de Distribuição, representada nas subsidiárias de varejo de alimentos Extra, Pão de Açúcar e Assaí Atacadista obteve sozinha um faturamento bruto de $\mathrm{R} \$ 76,9$ bilhões, cerca de $47 \%$ do faturamento das cinco maiores. Em segundo e em terceiro lugar estão respectivamente as empresas Carrefour e Wall Mart. A Tabela 1 apresenta o ranking das cinco maiores distribuidoras do varejo de alimentos, com o faturamento bruto de 2015 e o respectivo número de lojas.

Tabela 1- Ranking das cinco maiores empresas de distribuição no varejo de alimentos.

\begin{tabular}{|c|c|c|c|c|}
\hline Classificação & Empresa & Principais subsidiárias* & $\begin{array}{l}\text { Faturamento Bru- } \\
\text { to }(\mathrm{R} \$)\end{array}$ & $\begin{array}{l}\text { Nú mero } \\
\text { de lojas }\end{array}$ \\
\hline 1 & $\begin{array}{l}\text { Companhia Brasi- } \\
\text { leira de Distribui- } \\
\text { ção }\end{array}$ & $\begin{array}{l}\text { Extra, Pão de Açúcar, Assaí } \\
\text { Atacadista, Mini Extra, Minu- } \\
\text { to Pão de Açúcar }\end{array}$ & 76.933.000.000 & 2181 \\
\hline 2 & $\begin{array}{l}\text { Carrefour Com. } \\
\text { Ind. Ltda. }\end{array}$ & $\begin{array}{l}\text { Carrefour Hipermercado, Car- } \\
\text { refour Bairro, Carrefour Ex- } \\
\text { press, Atacadão }\end{array}$ & 42.701 .594 .004 & 288 \\
\hline 3 & $\begin{array}{l}\text { WalMart } \quad \text { Brasil } \\
\text { Ltda. }\end{array}$ & $\begin{array}{l}\text { WalMart hipermercado, Maxxi } \\
\text { Atacado, Sam's Club, Nacio- } \\
\text { nal, Big Hipermercados, Mer- } \\
\text { cadorama, TodoDia, Bompre- } \\
\text { ço }\end{array}$ & 29.323 .141 .083 & 485 \\
\hline 4 & $\begin{array}{l}\text { Cencosud Brasil } \\
\text { Comercial Ltda. }\end{array}$ & $\begin{array}{l}\text { GBarbosa, Mercantil Rodri- } \\
\text { gues, Perini, Bretas e Prezunic }\end{array}$ & 9.267 .780 .338 & 222 \\
\hline 5 & $\begin{array}{l}\text { Companhia Zaffari } \\
\text { Comércio e Indús- } \\
\text { tria }\end{array}$ & Zaffari, Bourbon & 4.508 .000 .000 & 31 \\
\hline
\end{tabular}

* As informações sobre as subsidiárias das empresas foram obtidas nos próprios sítios eletrônicos das mesmas.

Fonte: ABRAS (2016). 
A própria análise da variedade de subsidiárias dessas empresas revela a característica do processo de fusão e aquisição de empresas nacionais, o que tem sido uma estratégia recorrente para ampliar a participação no mercado ou até mesmo mantê-la e consequentemente eliminar a concorrência.

De 2015 para 2016, as principais redes de supermercados deram conta de que os problemas de mobilidade urbana estavam influenciando fortemente o comportamento dos consumidores de suas lojas. As grandes lojas, hipermercados localizados em áreas de grande circulação de veículos em vias expressas já não atraiam a clientela em virtude dos problemas de acesso, trânsito, estacionamento, etc. $\mid \mathrm{O}$ deslocamento de parte da demanda para lojas de vizinhança, menores e que haviam resistido ao tsunami das grandes redes foi a chave para que uma nova estratégia de operação fosse implementada.

Por intermédio de aquisições de cadeias de lojas familiares, locais e de menor porte, as grandes redes inauguravam um arranjo de lojas de vizinhança com características de lojas do bairro. Entre 2015 e 2016 as lojas de bairro saltaram das 61 unidades existentes para 614 em todo o Brasil, praticamente concentradas em grandes e médios centros urbanos (ABRAS, 2016).

Outra estratégia adotada pelos supermercados para ampliar a participação no mercado e concentrar a distribuição de alimentos gerando mais lucro foi a criação de marcas exclusivas, que geralmente apresentam preços menores que os similares das marcas líderes. No caso da Cia Brasileira de Distribuição, cinco marcas próprias de alimentos se difundem entre aproximadamente 900 produtos (Qualitá, Taeq, Casino, Club dos Sommeliers).

O fator de sucesso financeiro dos segmentos de supermercados está associado ao alto investimento em logística e a possibilidade de competir através dos preços, que associado ao aumento da escala de operações permitem a consolidação da concentração e impulsionando a lógica da fidelização e conveniência para os clientes (SAAB; GIMENEZ, 2000). O aumento da automação comercial, a modernização da tecnologia de informação e o aprimoramento de modelos de gestão também otimizaram a atuação desse setor.

Essas particularidades refletirão na relação estabelecida com os fornecedores dos supermercados. Operando sob condições de oligopólio, a autonomia dos fornecedores tende a ser muito fraca. Para garantir o fornecimento com o mínimo de riscos envolvidos, deve-se ter escala capaz de suprir a demanda de várias lojas ao mesmo tempo, além de organizar uma logística eficiente de distribuição até as centrais de expedição (GOMES JÚNIOR; ALY JÚNIOR, 2015).

Nesse sentido, a relação dos fornecedores com as redes de supermercados se dá 
de forma nociva para pequenos e médios produtores e fornecedores. Bezerra et al. (2016), salientam os mecanismos que o setor se utiliza para beneficiar-se dos seus fornecedores, tais como: diminuição da margem de lucro para os fornecedores; cobrança de taxas para a comercialização nas lojas; responsabilidade do prejuízo caso os produtos não sejam adquiridos; ameaças de quebra de contrato caso suas demandas não sejam atendidas.

Cabe destacar que essas vantagens competitivas e o aumento da escala de comercialização das grandes redes de varejo fragilizaram boa parte da concorrência. Esse movimento associado à internacionalização da grande distribuição comercial de autosserviço influenciou drasticamente na ruína dos aparelhos tradicionais de comercialização e do comércio de pequena escala, como as mercearias, armazéns, açougues, feiras livres.

A consolidação dos grandes supermercados trouxe consequências drásticas ao comércio tradicional existente, pois as lojas que vendem os mesmos produtos tiveram suas vendas reduzidas pela dificuldade de competir em preço, oferta e variedade de produtos com as grandes redes. De modo geral, o pequeno varejo sofre os impactos da migração dos consumidores para lojas de maior porte em busca de volumes maiores e preços mais atrativos.

As consequências do padrão internacionalizado das grandes foi demonstrado em um estudo da rede Amigos de la Tierra na Grã-Bretanha que verificou que o desaparecimento do pequeno comércio tem impacto direto na economia local, com diminuição da renda da comunidade. Enquanto 50\% dos lucros do comércio local realizado na forma de aparelhos tradicionais retornam ao município, apenas 5\% do lucro das grandes empresas de distribuição são reinvestidos (AMIGOS DE LA TIERRA, 2005). No Brasil, o impacto na economia local também pode ser verificado quando se observa que $87,3 \%$ do varejo de vizinhança é familiar (ABRAS, 2017).

Essas modificações nas condições de arranjo de comercialização das cidades alteraram a forma como a população lida com a aquisição de alimentos, tanto em relação ao espaço, quanto na definição do que é considerado alimento.

\section{A homogeneizaçÃo dos hábitos alimentares: COMIDA OU PRODUto} ALIMENTÍCIO?

A perda de capilaridade e diversidade das redes tradicionais de varejo e a consolidação do sistema de varejo moderno em larga escala, associado à necessidade frequente de aumentar o mix de produtos oferecidos ao consumidor impulsionaram o desenvolvimento da indústria de alimentos e consequentemente a modificação 
do padrão alimentar, substituindo produtos frescos e tradicionais em detrimento de alimentos industrializados. A introdução de novos produtos industrializados no cotidiano da população conduziu a uma progressiva diluição dos hábitos alimentares da relação entre a vida doméstica e o consumo e preparo dos alimentos.

Não menos ameaçador foi a construção no imaginário da sociedade que a modernidade se traduzia na possibilidade de a todo tempo e a qualquer tempo contar-se com uma oferta de alimentos que desconhece sazonalidade, nacionalidade, identidade cultural com as práticas e hábitos alimentares. A presença de frutas, legumes, verduras, grãos e até mesmo carnes exóticas nas prateleiras e unidades de frio nos supermercados levou que o consumidor cresse que a Cocanha da mitologia da Idade Média, a terra da primavera eterna (MONTANARI, 2013) convertera-se em realidade.

Nesse sentido, o aparecimento e crescimento das grandes redes oligopolizadas mudou radicalmente os hábitos de alimentação e consumo da população, subordinando essas necessidades básicas a uma lógica mercantil e aos interesses econômicos das grandes empresas. Ou seja, a distribuição e o consumo de alimentos deixa de estar associada às necessidades básicas da população e passa a ser determinada pelo que é rentável e lucrativo para o capital.

Para Steel (2008), as mudanças de processamento e distribuição dos alimentos foram decisivas para o afastamento da sociedade e da natureza, contribuindo de forma decisiva para a invisibilidade dos alimentos. Com o deslocamento da produção de alimentos para as margens, tanto em relação à geografia quanto na relação com as pessoas, os alimentos passaram a ser adquiridos em pré-prontos. Ao mesmo passo que a população foi gradualmente deixando de ter conhecimento sobre a procedência e formas de distribuição dos alimentos.

Outro fator decisivo está relacionado às condições de acesso aos alimentos na cidade. A intensificação da jornada de trabalho empurrou a aquisição de alimentos para lugares concentrados, que funcionam em horários estendidos e onde podese encontrar todos os itens antes adquiridos em diferentes estabelecimentos açougues, padarias, varejões e sacolões, mercearias, feiras - em um só lugar, como os supermercados. Ou seja, a aquisição de alimentos deixou de ser uma questão do que a população gostaria de comprar, mas do que estaria disponível a esses sujeitos, dadas as restrições de mobilidade física e horários disponíveis.

Segundo Wilkinson (2002), as mudanças na demanda de alimentos abriram novos flancos para atores apropriadores operando à montante (na produção rural) e os processadores, sobretudo com a transformação da linha de produtos baseados em commodities em especialidades e ingredientes saudáveis. 
Desse modo, o papel exercido pelo grande varejo passou a contestar a ideia dos consumidores ordenarem o sistema produtivo e ditarem a oferta de alimentos. $\mathrm{Ou}$ seja, as preferências dos consumidores passaram a ser cada vez mais relacionadas aos produtos ofertados pelos supermercados, os quais por serem cada vez mais concentrados dificultam a existência de locais que ofertem produtos diferentes dos comercializados nessas grandes redes (CUNHA, 2016), como é o caso da diminuição e desaparecimento dos aparelhos de abastecimento de vizinhança.

Desse modo, o papel exercido pelo grande varejo subordinou as preferências e escolhas dos consumidores à sua pauta. A escala em que operam os supermercados praticamente elimina a possibilidade de produtores locais ou mesmo regionais, de individualmente ingressarem no sistema como fornecedores. Os supermercados das grandes redes, na prática ordenam a produção de acordo com seus interesses comerciais e subordinam as operações de aquisições na produção por intermédio de suas plataformas. Essa forma de operação reflete uma oferta composta por um número restrito de variedades de frutas, legumes, verduras, domínio de grandes indústrias na oferta de mercadorias processadas, alimentares ou não, ao mesmo tempo em que inviabiliza pela concorrência, a existência de equipamentos de varejo que operem com outra lógica (CUNHA, 2016).

Nesse sentido, a escolha dos produtos nos supermercados é determinada por uma aliança entre o grande varejo com as agroindústrias alimentares para aumentar o consumo de produtos com sabores específicos, com altos teores de gorduras, açúcares e sódio (CUNHA, 2016).A maioria dos alimentos comercializados é processada com doses elevadas de aditivos químicos sintéticos, como corantes, conservantes, antioxidantes, espessantes, estabilizadores, intensificadores de sabor, reguladores de acidez, amidos modificados etc., conferindo aos produtos uma cor mais atraente, a aparência de recém-fabricado ou um sabor intenso (ESTEVE, 2017).

É importante destacar que esses alimentos ultraprocessados são, na verdade, formulações criadas pela indústria de alimentos, contendo apenas resquícios ou mesmo nada dos alimentos originais e com grandes quantidades de óleo, sal e açúcar. São considerados "produtos de conveniência", que vêm em uma caixa, podem permanecer meses numa prateleira, podem ser comidos durante o caminho e serem servidos sem a necessidade de ligar o fogão (DIAS; CHIFFOLEAU, 2016).

Com a disseminação dos produtos industrializados, a modificação dos hábitos alimentares se deu forma mais intensa e rápida. As novas técnicas de processamento e conservação pela via de envasamentos e refrigeração mais do que garantirem a estabilidade da oferta forneceram as condições necessárias para a racionalização dos tempos das pessoas, consumido num cotidiano de longas jornadas de trabalho 
e de crescentes problemas com deslocamentos entre o domicílio e os locais de trabalho. A artificialização da comida foi apresentada como a saída melhor para contornar a falta de tempo e livrar a todos das tarefas de produzir refeições ao invés de empregar o tempo disponível para descansar (LEDA, 2017).

As alterações no consumo também se baseiam em estratégias de marketing de promoção de hábitos alimentares para definir o padrão de escolha alimentar do consumidor, como o surgimento periódico de alimentos "milagrosos" e "saudáveis", que prometem perca de peso, controle do colesterol, fortalecimento do sistema imunológico, redução dos riscos de diabetes, entre outros. Esse enfoque revela como a indústria vem se apoderando de alimentos termogênicos e funcionais e levando o consumidor a adquirir apenas os alimentos desses segmentos produzidos de forma industrial, quando na verdade todos os alimentos in natura, ou seja, alimentos verdadeiros com pouca ou nenhuma transformação, podem ter um papel benéfico na saúde humana e uma função relevante em termos nutritivos.

A ampliação no consumo dos produtos ultraprocessados também está relacionada às estratégias mais sofisticadas de marketing e a questões logísticas, que desenvolveram mercadorias mais fáceis de estocar, transportar, exibir e conservar nas prateleiras (FISCHLER, 2007). Estratégias essas que estão disponibilizadas de forma mais fácil às grandes empresas transnacionais que dominam o ramo da distribuição. Cerca de $25 \%$ e $55 \%$ das compras nos supermercados são compulsivas, resultantes de estímulos externos, ou seja, baseadas na forma como os supermercados oferecem os produtos (ESTEVE, 2017).

O símbolo da modernidade do supermercado e a suposta autonomia de escolha do que comprar é uma falácia, em que toda a dinâmica estabelecida dentro de um supermercado tem um interesse ofensivo de marketing. Esteve (2017) pontua que tudo em um supermercado é concebido para incentivar a compra, comparando o papel do consumidor como o de uma cobaia em um laboratório, induzido por cores vivas, anúncios de ofertas e promoções, tamanho dos carrinhos e cestas, formas de disposição dos produtos nas prateleiras e até estreitamento dos corredores a fim de aproximar os consumidores. Patel (2008) acrescenta que a oferta dos supermercados não é baseada nas preferências dos consumidores, ou por características das estações climáticas ou geográficas de um território, mas pelo poder das corporações alimentares.

Os consumidores são encorajados a acreditar que a escolha individual os salvará dos males coletivos como a fome e a obesidade, mas é justamente essa liberdade de escolha que gesta esses males (PATEL, 2008). O autor acrescenta que não pode significar "liberdade de escolha" quando as opções nas gôndolas dos supermercados 
de cereais, por exemplo, apresentam mais de 20 marcas, mas todas contendo cereais açucarados, conservantes, aditivos químicos e sabores artificiais.

Dessa forma, a perda de autonomia na escolha de diferentes produtos é escamoteada por uma suposta variedade da oferta de alimentos, que ao serem produzidos utilizando cada vez menos culturas (principalmente soja e milho) e quantidades excessivas de açúcares e gorduras, substituem as variedades de alimentos frescos antes referenciados socialmente nos hábitos alimentares da população, como no caso da substituição da banha de porco pelo óleo refinado de soja. De acordo com Gomes Júnior e Aly Júnior (2015), há um estiolamento do próprio significado do que é comida, alterando todas as relações que a comida construiu com a história dos indivíduos e suas sociabilidades através dos tempos.

A contínua desconstrução das práticas alimentares também demarca a posição dominante e imperiosa da indústria de alimentos finais dentro do sistema agroalimentar, que segue a tendência de concentrar capitais. Uma campanha realizada pela ONG Oxfam intitulada Behind the Brands (Por trás das marcas) revela que apenas dez empresas multinacionais controlam uma parte importante do mercado mundial de alimentos. As empresas Nestlé, PepsiCo, Unilever, Mondelez, Coca-Cola, Mars, Danone, Associated British Foods (ABF), General Mills e Kellogg's faturam juntas US\$ 1,1 bilhão diariamente (OXFAM, 2016). A campanha da Oxfam também apresenta como uma mesma empresa congrega diferentes tipos de marcas e produtos, como, por exemplo, a Nestlé, que atua na produção industrial de produtos que variam de chocolates, cafés solúveis, temperos, ração de animais domésticos e até água engarrafada.

Outro exemplo é a empresa Cargill, a maior empresa no ramo do agronegócio brasileiro, que em 2016 teve um lucro líquido de R \$ 661,4 milhões. Além de atuar na produção de commodities agrícolas, atua no ramo de produção de rações animais, produtos alimentícios, tais como atomatados, maioneses, molhos para salada, óleos de cozinha, produtos farmacêuticos e cosméticos.

A forma como essas empresas controlam a cadeia de produção e processamento de alimentos está diretamente relacionada com o que é ofertado nos supermercados e comprado pelos consumidores. Nesse formato de concentração, as empresas é quem determinam o que o consumidor vai adquirir e não o contrário, ou seja, o consumidor até pode escolher marcar diferentes, mas estará comprando da mesma empresa. Conforme salienta Patel (2008), a comida que comemos não é produzida para nós, nós é que somos produzidos para a nossa comida.

Todas essas modificações na forma de produção, processamento e distribuição dos alimentos submetidas aos interesses das grandes empresas do sistema 
agroalimentar e à lógica comercial influenciaram radicalmente nos hábitos alimentares da população, aumentando o consumo de alimentos processados e congelados. Dados da Pesquisa de Orçamentos Familiares - POF 2008/2009 sobre tipo e a quantidade de alimentos adquiridos pelas famílias brasileiras apontam desequilíbrios nas dietas alimentares, bem como um aumento na frequência de consumo alimentar fora de casa (IBGE, 2010).

Em relação à evolução da disponibilidade de alimentos nos domicílios entre 2002-2003 e 2008-2009, a pesquisa revela que houve um aumento no consumo de alimentos ricos em gorduras, açúcares, como embutidos (25\%), refrigerantes (16\%), bebidas alcoólicas (28\%), refeições prontas e misturas industrializadas (40\%). Ao mesmo tempo em que houve diminuição do consumo de alimentos tradicionais na cesta básica brasileira como arroz, feijões, mandioca.

Apesar de consumir mais calorias, proteínas e gorduras, a alimentação contemporânea além de ser menos adequada nutricionalmente também é menos variada. De acordo com a FAO (2007; 2010), 75\% das variedades agrícolas desapareceram ao longo do século passado e $90 \%$ da alimentação mundial é baseada em apenas quinze variedades de cultivos agrícolas e na criação de oito espécies de animais.

A preferência pelo consumo de alimentos ultra - processados, energeticamente mais densos e baseados em poucas variedades agrícolas está diretamente relacionada ao aumento de doenças crônicas como diabetes, obesidade, problemas cardíacos e cânceres.

Isso ocorre, porque além de ter um perfil nutricional desequilibrado, baseado em sódio, açúcar, gordura e aditivos químicos que lhes conferem sabores e aromas artificiais, essas imitações de alimentos desregulam o metabolismo humano, pois não possuem vitaminas, minerais e fibras requeridos, fazendo com que gorduras e açucares sejam absorvidos muito rapidamente potencializando os agravos de saúde na forma da incidência de doenças crônicas não transmissíveis. Outra característica desse tipo de alimento é o fato de serem produzidos para tornarem-se viciantes e associados a sensações de prazer extremo ao mesmo tempo em que remetem a uma sensação de permanente insaciabilidade o que, ao fim e ao cabo, induzem ingestão muito além do que o necessário para o organismo humano.

Esses alimentos artificiais passaram a ser ofertados cada vez mais na forma de comida pré-preparada requerendo tão somente breve aquecimento em fornos micro-ondas nas suas próprias embalagens para converterem-se em refeições. A comida pré-preparada se encontra com outros símbolos da modernidade que evoca praticidade e rapidez em todas as tarefas como forma de se adaptarem a um cotidiano 
pressionado pela escassez de tempo para as atividades privadas.

Essa ideia de alimento prático vendida como expressão da vida moderna, tem se prestado a contribuir com a vulgarização da ideia de comida. Na medida em que a praticidade dos alimentos pré-preparados se torna mais presente na dieta das pessoas mais se distanciam as práticas e hábitos alimentares convencionais associados às rotinas do cozinhar, do tomar as refeições em família. Os novos hábitos tendem a diluir a percepção da compressão do espaço - tempo que se abate sobre a rotina dos citadinos a partir de uma noção de praticidade que se completa no consumo descuidado da comida na mesa do escritório, à frente da televisão ou do celular conectado às redes sociais. A vulgarização da comida come o sentido do que é uma refeição, banaliza hábitos e tradições alimentares por intermédio de uma miríade de preparos à disposição em qualquer supermercado ou loja de conveniência.

A aparente diversidade e praticidade dos itens ofertados pelo varejo moderno, a diminuição do tempo livre para aquisição e preparo dos alimentos, a supressão dos alimentos tradicionalmente consumidos pela população brasileira são fatores que causam a alteração dos ambientes alimentares, ocasionando situações de vazios alimentares no que tange ao acesso e qualidade da alimentação da população.

Um vazio alimentar, ou deserto alimentar, é um local de acesso limitado a alimentos nutritivos saudáveis, seja por falta de renda monetária, tempo, condições de mobilidade e/ou distância. Esses desertos alimentares não dizem respeito apenas às dificuldades em torno de espaços onde são possíveis acessar alimentos de qualidade, mas também à menor possibilidade de diversidade em decorrência do estreitamento do catálogo de produtos (STEEL, 2008).

Ou seja, apesar da evidência dos malefícios dos alimentos ultraprocessados, os alimentos in natura e frescos estão distantes do cotidiano de regiões mais afastadas e socialmente vulneráveis, relacionando a questão da alimentação com a necessidade de um planejamento urbano associado às necessidades básicas e diárias da população.

\section{CONSIDERações Finais}

A industrialização e distribuição de alimentos sob o controle de poucas empresas que dominam praticamente todas as cadeias do sistema junta-se à explosão dos números de doenças crônicas não contagiosas que atingem amplos setores da população que convivem com o excesso de peso associado a uma dieta sustentada no consumo de comida que não é comida, de comida que imita comida e dão forma à condição de insegurança alimentar e nutricional decorrente da subversão da ideia e significado do que é comida.

Para garantir a segurança alimentar e nutricional deve-se considerar a premissa da oferta permanente e em quantidade suficiente de alimentos. Para Gomes Júnior 
(2015), essa oferta deve estar disponível e ser apropriada internamente, de forma que não impeça a demanda agregada de alimentos por assimetrias entre procura e disponibilidade ou por instabilidade nos preços.

No entanto, um quadro de segurança alimentar e nutricional também deve abordar "aspectos relacionados às técnicas de produção e pesquisa agrícolas, à matriz industrial de transformação e processamento, à propaganda, ao meio ambiente, à autonomia do país em produzir e consumir aquilo que é parte das tradições de seu povo" (GOMES JÚNIOR, 2015, p.15).

Nesse sentido, somado à necessidade de democratizar a produção agrícola e a distribuição de alimentos, dois importantes pontos de enfoque em torno da garantia da segurança alimentar e do abastecimento alimentar urbano dizem respeito às políticas públicas e ao mercado consumidor.

Cassol e Schneider (2015) sugerem que essa interação se dê entre as formas de produzir e comercializar e os modos de consumir e se alimentar, a fim de aprimorar o campo de ação das políticas públicas e o papel dos atores e mediadores sociais, bem como suas formas de organização.

Diante da ótica das políticas públicas de abastecimento alimentar e da garantia de segurança alimentar, Maluf (1999) destaca a importância do Poder Público promover e estimular ações que contribuam para um sistema integrado de abastecimento, que contemple aspectos da produção e distribuição dos alimentos em formas mais equitativas.

Além da promoção de ações equitativas, que garantam a produção diversificada e suficiente, assim como a distribuição em quantidade e regularidade necessárias, a garantia da manutenção da oferta de alimentos envolve também a constituição de estoques reguladores, estratégicos e de emergência, sob controle de um governo central que intervenha no mercado central e promovam políticas assistenciais de distribuição de alimentos (GOMES JÚNIOR, 2015).

Nesse sentido, é preciso levar em conta que as ações de abastecimento devem propiciar o acesso aos alimentos por todos os segmentos da população, em quantidade e qualidade apropriada. Contudo, Gomes Júnior (2015) ressalta que a garantia de acesso regular e permanente aos alimentos se reporta às condições para a realização do direito humano à alimentação. Essas condições não estão ligadas apenas à sincronização dos preços dos alimentos com a renda disponível para a sua aquisição, mas decorrem das restrições ao acesso de alimentos relacionadas às falhas nos arranjos de desenvolvimento social e econômico, como, por exemplo, problemas ambientais, desemprego, falhas na saúde e na educação pública.

Esse processo se soma à estratégia da "democracia alimentar", defendida por Lang (2009), que trabalha a incorporação do princípio da cidadania alimentar 
em termos de iniciativas que melhorem a alimentação de toda a população, e não apenas de uma parte dela. É nesse âmbito que se destaca o conceito da soberania alimentar, cunhado para ser um contraponto ao modelo de produção do agronegócio, das políticas que transformam os alimentos em mercadorias e que visam atender a segurança alimentar de toda a população.

Dessa forma, a proposta de soberania alimentar se materializa no direito que cada país tem em além de acessar aos alimentos, produzi-los a partir de suas próprias políticas e estratégias sustentáveis, lhes garantindo soberania sobre suas existências (STÉDILE, CARVALHO, 2011).

Assim a Soberania Alimentar se torna a via possível para garantir a Segurança Alimentar da população, através da realização do direito humano à alimentação adequada, que se concretiza no acesso regular a alimentos de qualidade e em quantidades suficientes, tendo como base práticas alimentares adaptadas às tradições e diversidades culturais que assegurem a promoção de saúde e sejam sustentáveis do ponto de vista social, econômico e ambiental

Cunha (2016) trabalha com o conceito do "Novo-Ancestral", para afirmar que não se trata mais de apenas reconfigurar a cadeia de fornecimento ou de restabelecer a autonomia da preferência do indivíduo em suas decisões de consumo. Para o autor, trata-se do reconhecimento de novos valores atribuídos aos alimentos, que expressam a qualidade e a representação social ou local. Ou seja, é a valorização de elementos ligados ao local de produção, às variedades ofertadas, à forma de produção e apresentação dos produtos, os quais são refletidos na valorização dos produtos que estabelecem conexões e associações com as relações sociais do processo produtivo (origem do produto). Toda essa configuração é marcada pela mediação da pessoalidade das relações comerciais da escolha, avaliação e negociação do produto, que envolvem vínculos de confiança com o vendedor.

Reivindicar a soberania alimentar e uma nova forma de organização da produção, distribuição e consumo de alimentos, não implica retornar a um passado arcaico e nem a uma abordagem localista, conforme aponta Esteve (2017), mas de formas de promover um sistema alimentar mundial democrático, a serviço do bem-estar e da garantia de sobrevivência digna dos seres humanos.

Diante do exposto, considera-se que o sistema de abastecimento alimentar deve ser tema central nas discussões sobre Segurança Alimentar e Soberania Alimentar, tendo em vista seu papel no aprimoramento dos canais de comercialização e das formas de acesso mais justas à alimentos diversificados e seguros.

\section{REFERÊNCIAS}


ABRAS - ASSOCIAÇÃO BRASILEIRA DE SUPERMERCADOS. Pequeno Mercado Eficiente. SuperHiper, São Paulo, jun., 2017.

ABRAS - ASSOCIAÇÃO BRASILEIRA DE SUPERMERCADOS. Ranking ABRAS 2016. SuperHiper, São Paulo, abr., 2016.

BELIK, W. Muito além da porteira: Mudanças nas formas de coordenação da cadeia agroalimentar no Brasil. 1999. 146p. Tese (Doutorado em Economia) - Instituto de Economia, Universidade de Campinas, Campinas, 1999.

BEZERRA, J. E.; AGNER, M, R.; AZEVEDO FILHO, G. L. S. A expansão das redes de supermercado em Brasília (DF). In: Encontro Nacional de Geografia Agrária, 23., 2016, São Cristóvão. Anais... São Cristóvão: UFS/Programa de PósGraduação em Geografia, 2016.

BRASIL, Ministério da Saúde. Vigitel Brasil 2016: vigilância de fatores de risco e proteção para doenças crônicas por inquérito telefônico: estimativas sobre frequência e distribuição sociodemográfica de fatores de risco e proteção para doenças crônicas nas capitais dos 26 estados brasileiros e no Distrito Federal em 2016. Brasília: Ministério da Saúde, 2017.

CASSOL, A. SCHNEIDER, S. Produção e consumo de alimentos: novas redes e atores. Lua Nova, São Paulo, v. 95, p. 143-177, 2015.

CUNHA, A. R. A. A. Abastecimento alimentar: a superação do padrão VelhoObsoleto para o Novo-Ancestral. In: CRUZ, F. T.; MATTE, A.; SCHNEIDER, S. (Orgs.). Produção, consumo e abastecimento de alimentos: desafios e novas estratégias. Porto Alegre: UFRGS, 2016. p. 53-69.

CYRILLO, D. C. O papel dos supermercados no varejo de alimentos. São Paulo: IPE/USP, 1987.

DIAS, J.; CHIFFOLEAU, M. Surpresa: indústria alimentícia com pinta de "saudável". (2016). Disponível em: <https://outraspalavras.net/brasil/surpresaindustria-alimenticia-pretende-se-saudavel/>. Acesso em: 24 jan. 2019.

ESTEVE, E. V. O negócio da comida - quem controla nossa alimentação?. São 
Paulo: Expressão Popular, 2017.

FAO - FOOD AND AGRICULTURE ORGANIZATION OF THE UNITED NATIONS. (2016). The State of Food Insecurity in the World 2013. Disponível em: <http://www.fao.org/docrep/018/i3458e/i3458e.pdf>. Acesso em: 25 fev. 2019.

FAO - FOOD AND AGRICULTURE ORGANIZATION OF THE UNITED NATIONS. (2018). El estado de la seguridad alimentaria y la nutrición en el mundo 2017 - Fomentando la resiliencia climática en aras de la seguridad alimentaria y la nutrición. Roma: FAO/FIDA/OMS/PMA/UNICEF, 2018.

FAO-FOOD AND AGRICULTURE ORGANIZATION OF THE UNITED. (2007). La ADRS y la agrobiodiversidad. Agricultura y desarrollo rural sostenible. Disponível em: <ftp://ftp.fao.org/sd/sda/sdar/sard/SARD-agroecology\%20-\%20 spanish.pdf>. Acesso em: 25 jan. 2019.

FAO - FOOD AND AGRICULTURE ORGANIZATION OF THE UNITED. (2010). Biodiversidad agrícola: utilizarla para que no si perda Disponível em <www.fao.org.news/story/es/item/46805/icode/>. Acesso em: 25 jan. 2019.

FARINA, E. M. M. Q; NUNES, R.; MONTEIRO, G. F. A. Supermarkets and their impacts on the agrifood system of Brazil: the competition among retailers. Agribusiness, v. 21, n. 2, p. 133-147, 2005.

FISCHLER, C. A "McDonaldização" dos costumes. In. FLANDRIN, J. L.; MONTANARI, M. (Orgs.). História da alimentação. 6.ed. São Paulo: Estação Liberdade, 2007. p. 841-862.

GOMES JÚNIOR, N. N. Segurança Alimentar e Nutricional e Necessidades Básicas Humanas. São Paulo: Perseu Abramo, 2015.

GOMES JÚNIOR, N. N.; ALY JÚNIOR, O. Soberania alimentar e agronegócio: notas além da porteira. Retratos de Assentamentos, Araraquara, v. 18, n. 2, p. 305-319, 2015.

GTSCA2013 - GRUPO DE TRABALHO DA SOCIEDADE CIVIL PARA AGENDA 2030. Relatório Luz da Agenda 2030 de Desenvolvimento Sustentável. 
Disponível em: < https://brasilnaagenda2030.org>. Acesso em: 25 fev. 2019.

IBGE - INSTITUTO BRASILEIRO DE GEOGRAFIAE ESTATÍSTICA. Pesquisa de Orçamentos Familiares 2008/2009. Rio de Janeiro: IBGE, 2010.

LANG, T. Reshaping the food system for ecological public health. Journal of Hunger \& Environmental Nutrition, v.4, n.3, p. 315-35, 2009.

LEDA, L. C. Sistema tradicional de varejo de alimentos e sua importância para a segurança alimentar: o caso do Distrito Federal. 2017. 130p. Dissertação (Mestrado em Meio Ambiente e Desenvolvimento Rural) - Programa de PósGraduação em Meio Ambiente e Desenvolvimento Rural, Faculdade UnB Planaltina, Universidade de Brasília, Planaltina, 2017.

MALUF, R. S. Ações Públicas locais de abastecimento alimentar. Polis Papers, São Paulo, n.5, 1999.

MAZON, M. S. Abastecimento alimentar no Brasil e as reformas liberalizantes: Estado e mercado em questão. 2010. 249p. Tese (Doutorado em Sociologia Política) - Programa de Pós-Graduação em Sociologia Política, Centro de Filosofia e Ciências Humanas, Universidade Federal de Santa Catarina, Florianópolis, 2010.

MONTATARI, M.; Comida como Cultura. São Paulo, Editora SENAC, 2013.

MONTANARI, M.; FLANDRIN, J. L. História da alimentação. São Paulo: Estação Liberdade, v. 2, 1998.

OXFAM. (2016). Behind the Brands. Disponível em: <https://www. behindthebrands. org/brands/ $>$. Acesso em: 20 jan. 2019.

PATEL, R. Stuffed and Starved. New York: Melville House, 2007.

REARDON, T.; BERDEGUÉ, J. A. The rapid rise of supermarkets in Latin America: challenges and opportunities for development. Development policy review, v.20, n.4, p. 371-388, 2002.

ROJO, F. J. G. Supermercados no Brasil: qualidade total, marketing de serviços, 
comportamento do consumidor. São Paulo: Atlas, 1998.

SAAB, W. G. L.; GIMENEZ, L. C. P. (2000). Aspectos atuais do varejo de alimentos no mundo e no Brasil. Disponível em: <http://www.bndes.gov.br $>$. Acesso em: 05 fev. 2019.

SILVEIRA, M. L.; SANTOS, M. O Brasil: território e sociedade no início do século XXI. Rio de Janeiro: Record, 2001.

STÉDILE, J. P.; CARVALHO, H. M. Soberania alimentar: uma necessidade dos povos. (2011). Disponível em: $<$ https://www.ecodebate.com. br $>$. Acesso em: 10 out. 2018

STEEL, C. Hungry city. How food shapes our lives. London: Chatto\&Windus, Vintade, 2008.

SUPERMERCADO MODERNO. 39 Relatório anual: Ranking do autosserviço. São Paulo, abr., 2010.

WILKINSON, J. Os gigantes da indústria alimentar entre a grande distribuição e os novos clusters a montante. Estudos Sociedade e Agricultura, Rio de Janeiro, v.18, p.147-174, 2002.

ZIEGLER, J. Destruição massiva: Geopolítica da fome. São Paulo: Cortez, 2012. 